\title{
Atmospheric Corona Discharge Plasma for Rice (Oryza sativa L.) Seed Surface Modification, Fungi Decontamination, and Shelf Life Extension
}

\author{
Khomsan Ruangwong, ${ }^{a}$ Thunyapuk Rongsangchaicharean, ${ }^{\mathrm{b}}$ \\ Chayaporn Thammaniphit, a Damrongvudhi Onwimol, ${ }^{\mathrm{b}}$ \& Siwapon Srisonphan ${ }^{\mathrm{a}, *}$ \\ aDepartment of Electrical Engineering, Faculty of Engineering, Kasetsart University, Ladyao, \\ Chatuchak, Bangkok, Thailand; 'Department of Agronomy, Faculty of Agriculture, Kasetsart \\ University, Ladyao, Chatuchak, Bangkok, Thailand

\begin{abstract}
*Address all correspondence to: Siwapon Srisonphan, Department of Electrical Engineering, Faculty of Engineering, Kasetsart University, 50 Ngamwongwan Road, Ladyao, Chatuchak, Bangkok 10900, Thailand; Tel.: +66-85-499-9641, E-mail: siwapon.s@ku.th
\end{abstract}

\begin{abstract}
We demonstrate atmospheric corona plasma can modify rice (Oryza sativa L.) seed surface wettability and eliminate attached microorganisms at ambient temperatures, which can enhance germination and extend shelf life. High electric field strength up to $10^{5} \mathrm{~V} / \mathrm{cm}$ at the electrode tips is the critical factor for generating corona discharge plasma and, consequently, providing reactive oxygen and nitrogen species (RONS) via electron-induced impact ionization. We show that the reactive species and ions are primarily responsible for enhanced seed surface wettability via water imbibition (WI) and apparent contact angle (ACA) measurement. A scanning electron microscope was employed to confirm that the cold corona plasma treatment can decontaminate seedborne pathogenic fungi. Sterilized seeds with better surface wettability are more likely to germinate and yield higher quality seedlings. In addition, we demonstrate the potential use of the corona plasma process for seed storage extension and quality retention through accelerated aging germination and decreased moisture content. Germination of treated seed after passing accelerated aging process is approximately $90 \%$, similar to that of unaged and untreated seeds.
\end{abstract}

KEY WORDS: nonthermal plasma, water imbibition, surface wettability, seed longevity, Oryza sativa, seed germination, disinfection

\section{INTRODUCTION}

Pathogenic fungi can decrease the biological and physical quality of agricultural products before and after harvesting. ${ }^{1-4}$ Fungal infestation can damage stored seeds, producing undesirable odors and colors and lower the germination and seed quality. ${ }^{2}$ Most importantly, fungal infestation in crops has a significant impact on food and agricultural industries and has become a severe economic problem for exporting food products in many countries. ${ }^{1,2}$ Therefore, the elimination of harmful pathogenic fungi on crops is crucial for agriculturally supplied countries. Eliminating fungal infestation is challenging because microorganisms and spores are resistant structures. ${ }^{3-6}$ As a single-celled or complex multicellular microorganism, fungi can invade crops and food in several ways, such as soil, wind, water, or spores in the air. Therefore, food and seedborne pathogen 
outbreaks have been a challenge for the fresh produce industry. ${ }^{4,5}$ Chemical fungicides are a traditional method for decontaminating or inactivating microorganisms. ${ }^{3,5}$ However, chemical fungicide residues can harm health and the environment. ${ }^{3,5}$ In addition, antifungal chemical agents are generally expensive and increase the product cost.

Rice is one of the main staple foods for humans. ${ }^{7,8}$ However, rice seed production has been directly harmed by seedborne pathogens either on the seed surface or the inner tissue of the seed even before planting. ${ }^{3,5,9}$ During harvesting and storage, seedborne pathogens can contaminate rice seeds, furthermore affecting rice production..$^{3,5,8,9}$ Although chemical fungicides leave behind toxic residues on food crops, like other crops, they are also used for eliminating the attached microorganisms and pathogenic fungi to prevent disease development in rice production. In recent decades, atmospheric cold plasma has shown promising results for possibly inactivating pathogens without adverse effects on nutritional content of the seeds. Various cold plasma sources, structures, and working principles have been developed over time and have individual characteristics, such as coronas, plasma jet, dielectric barrier discharges (DBDs), and microwave discharges for different applications. ${ }^{10-14}$ In this work, we demonstrate the use of atmospheric corona discharge plasma to decontaminate food and biological materials.

Herein we present the use of cold plasma based on corona discharge as a promising method for seed sterilization, germination enhancement, and prolonged seed longevity. We then discuss which plasma components interact on the rice seed surface, resulting in fungal inactivation and seed surface modification. The enhancement of surface wettability (apparent contact angle measurement [ACA] and water imbibition [WI]) was discussed with supporting evidence from scanning electron microscopy (SEM) images. Subsequently, we presented seed germination enhancement before and during 60 day storage. In addition, the effect of plasma treatment on moisture content (\% MC) of rice seed was presented.

\section{RESULTS AND DISCUSSION}

The atmospheric corona discharge plasma configuration was designed based on the conventional points-to-plane electrode (Fig. 1a) ${ }^{14,15}$ (see Materials and Methods). An array of tungsten tips with a sharp edge with $200 \mu \mathrm{m}$ curvature radius was employed to create the highly localized electric field (E-field) (up to $5 \times 10^{4} \mathrm{~V} / \mathrm{cm}$ ) around the tip edge (see Fig. 1c). Such highly localized electric fields can cause gas breakdown. ${ }^{15}$ resulting in corona discharge as a self-sustaining, nonluminous filament propagating from the tip edge to the grounded electrode (see Fig. 1b). However, an insulator layer is needed in this structure to prevent arc (thermal plasma) formation and to stabilize cold plasma generation and its impact ionization process, ${ }^{10,11,14-16}$ by placing a $1 \mathrm{~mm}$ thick glass plate on top of the bottom planar ground electrode (see Fig. 1a). As a result, this structure generates a microcorona discharge-initiated streamer plasma that propagates in the entire area under atmospheric air ambient conditions (see Fig. 1b). In this work, air mixed with argon (air/Ar) is the primary working gas to achieve a large volume of nonthermal streamer plasma (see Fig. 1b) with exceptionally low electrical power $\left(1 \mathrm{~W} / \mathrm{cm}^{2}\right)$ and to lessen the energy transferred from electrons and ions to the seed, ${ }^{11}$ leading to gentle 
a
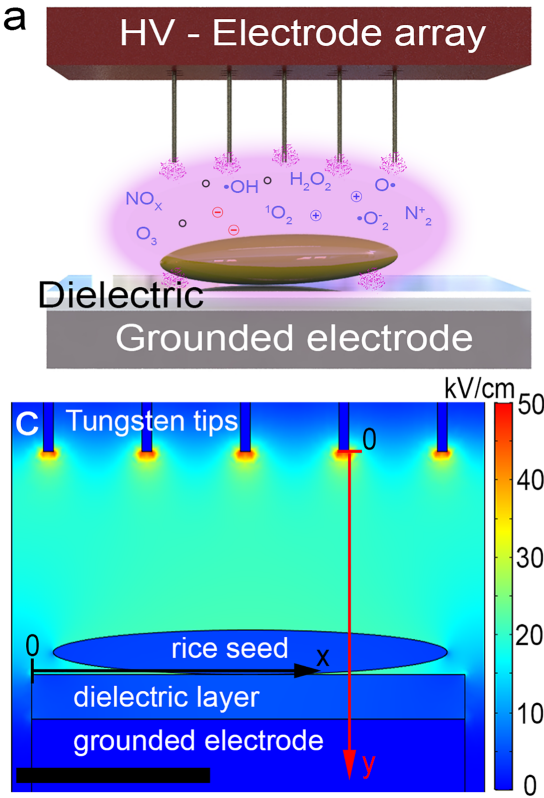
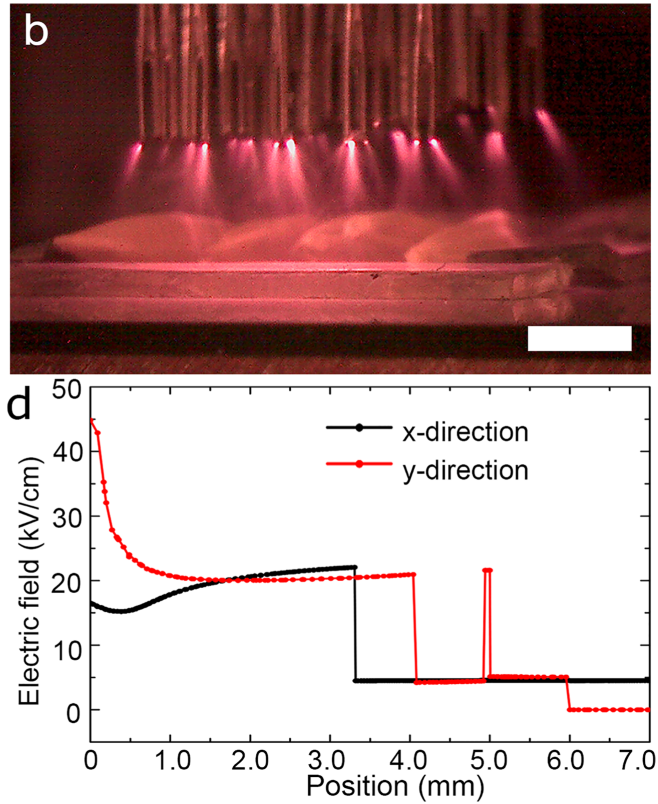

FIG. 1: Atmospheric corona discharge plasma configuration. (a) The overall setup of corona discharge plasma on rice seed placed on the dielectric layer. (b) Optical image of corona discharge plasma treatment on rice seeds during operation (scale bar, $4 \mathrm{~mm}$ ). (c) The overall electric field distribution simulated using a finite-element method (scale bar, $5 \mathrm{~mm}$ ). (d) The electric field distribution underneath the seed, horizontally along the dielectric layer ( $x$-direction), and vertically from the tip edge through the seed ( $y$-direction).

surface modification (see Materials and Methods). This microcorona discharge provides cold plasma at atmospheric pressure with the temperature close to room temperature, suitable for temperature-sensitive material applications.

Figure 1c demonstrates the corresponding E-field distribution simulated by the finite element method (FEM) using COMSOL Multiphysics. The relative permittivity of $10 \%$ $\mathrm{MC}$ rice seed is $\sim 5 .{ }^{17}$ The FEM suggests that two localized E-field region build up in the system, causing gaseous breakdown and microdischarge. The E-field is distributed along the $y$-direction from tip edge to the bottom electrode (see Fig. 1d, red line or $y$ direction) and along the $x$-direction, underneath the rice seed along the dielectric surface (see Fig. 1d, black line or $x$-direction). The peak E-field underneath the seed surface is up to $3 \times 10^{4} \mathrm{~V} / \mathrm{cm}$, whereas the E-field around the tip edge is approximately $5 \times 10^{4} \mathrm{~V} /$ $\mathrm{cm}$. Both E-fields can break down unstable pure air and air-Ar, allowing generation of the microcorona discharge plasma. Note that the dielectric breakdown strength of pure air and $\mathrm{Ar}$ is $30 \mathrm{kV} / \mathrm{cm}$ and $6 \mathrm{kV} / \mathrm{cm}$, respectively. ${ }^{10,18}$ In the electrical discharge plasma system, a highly localized E-field is crucial for the electron emissions process and, consequently, induced impact ionization. ${ }^{14,16,19}$ Electrons with high kinetic energy can travel in the air within the length of the mean free path $(\sim 100 \mathrm{~nm})^{20,21}$ before colliding with 
the gas atoms, molecules, electrons, and ions, resulting in gas breakdown. Besides, electrons and ions within the gas can conduct a small current, disturbing the equilibrium and resulting in the generation of several active plasma chemical species (see Fig. 3e).

Figure 2 illustrates the optical emission spectroscopy (OES) of corona discharge plasma in atmospheric air mixed with Ar (green line) and pure ambient air (blue line). The OES qualitatively reveals the types of reactive species in the plasma (see Materials and Methods). The optical spectrum primarily corresponds to reactive oxygen species (ROS) and reactive nitrogen species (RNS) because nitrogen $(\sim 75 \%)$ and oxygen $(\sim$ $20 \%$ ) are the main components of the air. ${ }^{18}$ The spectral peaks in the ultraviolet-visible (UV-Vis) range correspond to excited nitrogen. ${ }^{22}$ In this work, a low level of Ar was supplied to the corona area with a flow rate of 1 to $2 \mathrm{~L} / \mathrm{min}$ from $5 \mathrm{~cm}$ away to increase the
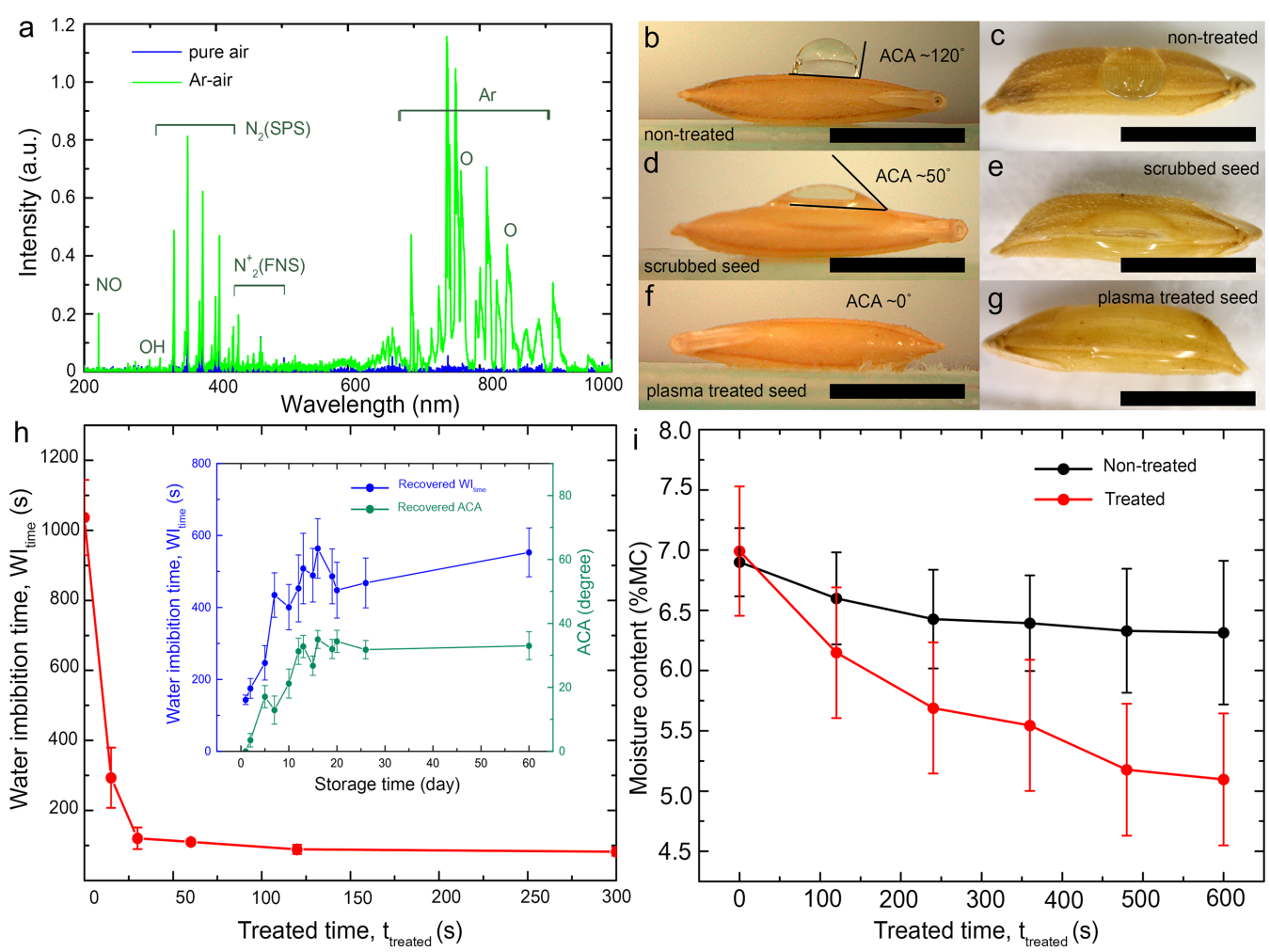

FIG. 2: Surface wettability and corona plasma components. (a) Optical emission spectra (OES) of corona plasma at different ambient conditions; a mixture of Ar-air (green line) and pure air (blue line). The comparison of measured apparent contact angle (ACA) of (b, c) untreated $\left(120^{\circ}\right)$, (d, e) scrubbed seed $\left(50^{\circ}\right)$, and (f, g) the mixture air-Ar plasma treated seeds $\left(0^{\circ}\right)$, respectively (scale bar, $4 \mathrm{~mm}$ ). (h) Water imbibition enhancement of treated rice seed at different treatment times. (Inset) The recovered water imbibition and ACA during storage for 60 days. (i) The moisture content of rice seed after the corona plasma application. The error bar presents means $\pm 2 \mathrm{SD}$ ( $n=50$ ), indicating that $95 \%$ of data points deviations were within the error bars. 


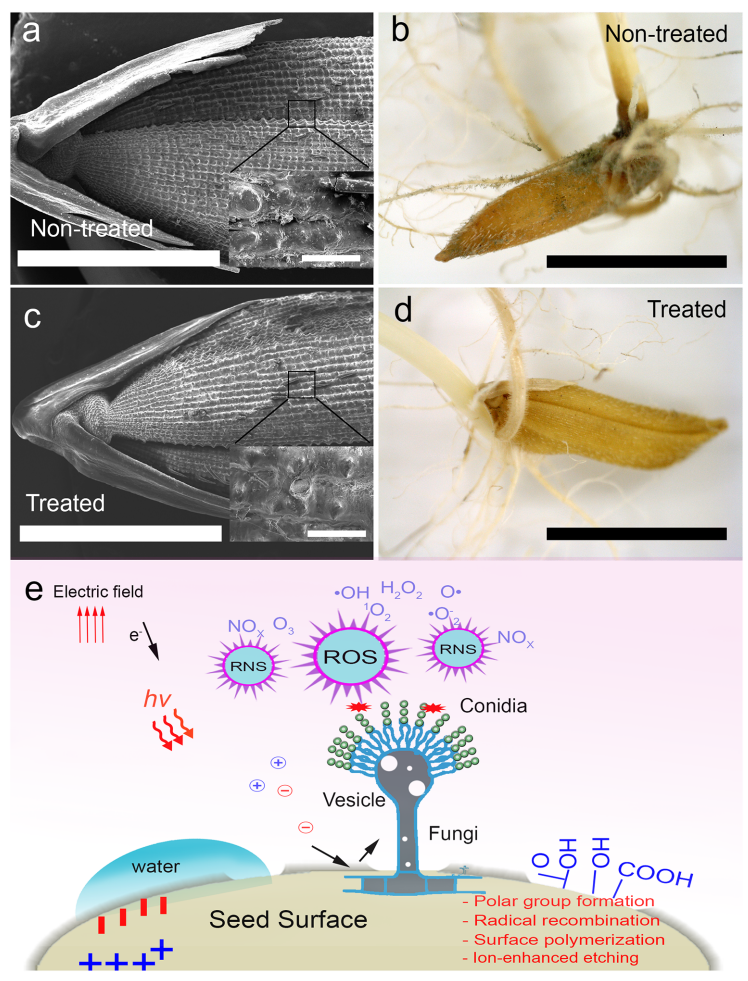

FIG. 3: Rice (Oryza sativa L.) seed surface morphology and day 14 seedlings. SEM micrographs of (a) untreated rice seeds, and (c) cold plasma-treated rice seeds (scale bars, $2 \mathrm{~mm}$; inset scale bar, $50 \mu \mathrm{m}$ ). Inset of (a) and (c) showing the microorganism living along the trench. Day 14 rice seedlings (b) without and (d) with cold plasma treatment before planting. (e) Interactions between the cold plasma components and the seed surface with attached fungi.

impact ionization process and subsequent generation of ROS and RNS. ${ }^{6,23}$ ROS such as hydroxyl radicals $(\cdot \mathrm{OH})$ at $309 \mathrm{~nm}$, singlet oxygen molecules $\left({ }^{1} \mathrm{O}_{2}\right)$, superoxide anions $\left(\cdot \mathrm{O}_{2}^{-}\right)$, and ozone $\left(\mathrm{O}_{3}\right)$ were observed in the OES, and those have been known to effectively inactivate microorganisms and to modify the surface..$^{11,23-26}$

To substantiate the effects of nonthermal corona plasma for seed surface alteration, related to wettability enhancement, we exposed rice seeds to corona plasma for approximately 2 min. ACA and WI were then measured by placing a $2 \mu \mathrm{L}$ water droplet on top of the seed surface (see Materials and Methods). Figures $2 b$ and $2 c$ demonstrate the side view and top view, respectively, of untreated seeds after droplet application, whereas Fig. $2 \mathrm{f}$ and $2 \mathrm{~g}$ demonstrate those of treated seed. The results show that the average ACA of untreated seeds is $120^{\circ}$ (see Fig. 2b) and will be reduced significantly to $0^{\circ}$ after plasma application (see Fig. $2 \mathrm{f}$ and $2 \mathrm{~g}$ ). ACA was measured for 50 seeds, and the presented optical images illustrate the most representative data. In addition, the water imbibition (WI) of treated seeds becomes significantly faster than that for the natural seed surface (see Fig. $2 \mathrm{~h})$. For example, the average water imbibition time $\left(\mathrm{WI}_{\text {time }}\right)$ of the original seed surface 
is approximately $20 \mathrm{~min}$ to absorb a $2 \mu \mathrm{L}$ water droplet, whereas the treated seed $(2 \mathrm{~min}$ treatment time) requires 2 min to completely take up the water droplet. To observe the WI enhancement characteristic of rice seed after plasma applications, we performed plasma treatment on rice seed with different treatment times (from 0 to $5 \mathrm{~min}$ ) and measured the corresponding $\mathrm{WI}_{\text {time }}$. Figure $2 \mathrm{~h}$ shows that $\mathrm{WI}_{\text {time }}$ of treated seeds is significantly shorter than $\mathrm{WI}_{\text {time }}$ of original seed surface. The $\mathrm{WI}_{\text {time }}$ is abruptly reduced to 5 min after treatment for 15 seconds, and $\mathrm{WI}_{\text {time }}$ is gradually reduced to $2 \mathrm{~min}$ after plasma treatment for $2 \mathrm{~min}$. However, if rice seed was continually exposed to the plasma, there was no observable change in $\mathrm{WI}_{\text {time }}$. Therefore, the minimum of $\mathrm{WI}_{\text {time }}$ can be considered as water imbibition saturation time $\left(\mathrm{WI}_{\text {sat }}\right)$. The $95 \%$ reduction of $\mathrm{WI}_{\text {time }}$ after plasma treatment indicates the significance of seed surface modification via chemical formation, surface functionalization, and physical etching, ${ }^{9,19,25}$ as presented in Fig. 3e.

However, it is known that cold plasma can be used in many semiconductor industries for the etching process. ${ }^{27}$ Apparently, it raises two obvious questions: (1) Are seed wettability properties enhanced only by physical etching of the seed surface? and (2) How long does it take for the modified surface to recover? To determine whether the etching process enhanced surface wettability, we gently scrubbed the rice seed surface and performed the wettability test. The result showed that the ACA of the scrubbed surface is $50^{\circ}$ (see Fig. $2 \mathrm{~d}$ and $2 \mathrm{e}$ ), lower than that for the original surface $\left(120^{\circ}\right)$, but not comparable to the plasma-treated seed $\left(0^{\circ}\right)$. On the other hand, the $\mathrm{WI}_{\text {time }}$ of scrubbed seeds is $20 \mathrm{~min}$, which is in the range of that for untreated seeds, indicating that the etching process alone does not effectively modify the surface. Therefore, the plasma components such as reactive oxygen and nitrogen species (RONS) and ions are needed for surface functionalization. In addition, modified seed surface wettability may return to the original state after storage for a particular time, and the treatment may need to be repeated. Therefore, the recovery information of treated seed wettability is essential for storage systems. We performed the wettability test on plasma-treated seeds every 2 to 3 days for 60 days (see Fig. $2 \mathrm{~h}$ ). The overall results demonstrate that the hydrophobic characteristic of the treated seed surface recovered to some extent. We observed not only hydrophobic recovery but also WI restoration. The inset of Fig. $2 \mathrm{~h}$ shows that, during the first 10 days after storage, the ACA and $\mathrm{WI}_{\text {time }}$ slightly increase over time and then remain almost constant for 2 months. After storage for 60 days, the $\mathrm{WI}_{\text {time }}$ increased to $10 \mathrm{~min}$, and the ACA increased to $40^{\circ}$. Thus, these results suggest that retreatment may not be needed at least for 2 months after the first plasma treatment. Although the stored plasmatreated seed surface's wettability is degraded (slower WI, higher ACA) relative to measurements taken immediately after treatment, it is still much better than the fresh untreated seeds. For example, after stored for 2 months, the $\mathrm{WI}_{\text {time }}$ and the ACA of plasma-treated seed are $50 \%$ and $75 \%$, lower than the fresh untreated seeds, respectively. Therefore, the pathogenic decontamination and wettability enhancement after prolonged storage indicate that cold plasma treatment is a promising method that can improve and extend the shelf life of rice seeds while minimizing the effects on the nutritional and quality attributes. 
Figure $2 \mathrm{i}$ shows the moisture content $(\% \mathrm{MC})$ of rice seed after treatment at different times from 0 to $10 \mathrm{~min}$. We found that the $\% \mathrm{MC}$ of the treated seed (Fig. 2i, red line or treated) was slightly lower compared to the control seed. The longer treatment time can cause the seed become slightly drier and make it suitable for storage. SEM analysis was performed on treated and untreated rice seed to investigate the rice seed morphology before and after plasma treatment. The SEM image (see Fig. 3c) demonstrates the seed coat surface morphology of the treated seed, which is slightly drier and has more ruptures than the untreated seed (see Fig. 3a). The SEM image confirms that the rice seed surface was physically modified by the etching process, leading to enhanced wettability. In addition, the SEM images indicate that cold plasma can sterilize the surface by reducing and removing some microorganisms and pathogenic fungi attached along the seed surface's trench. This is possible because the plasma components, especially the reactive oxygen and nitrogen species such as $\mathrm{NO}_{x}, \mathrm{OH}, \mathrm{O}, \mathrm{H}_{2} \mathrm{O}_{2}$, and $\mathrm{O}_{3}$, can damage the cell walls and cell membranes of pathogenic fungi. ${ }^{11,24-26}$ Plasma components can break the conidiophores and the vesicle, resulting in cell wall destruction and allowing the leakage of intracellular components. (see Fig. 3e), ${ }^{4,14,16,19,23}$ In addition, cold plasma components can remove fungi attached on the rice seed husk by etching the surface, breaking the chemical bonds and inducing stress in the membranes. ${ }^{14,16,23}$ Therefore, overall results suggest that cold plasma treatment with a mixture of ions, electrons, exited atoms, and RONS can modify the seed surface to be highly hydrophilic and inhibit most microorganisms. The SEM image confirms that atmospheric corona plasma treatment can change the seed surface morphology and make it drier, cause it to rupture and flatten, and remove pathogenic fungi. A diagram of the mechanisms of plasma interaction on the seed surface for fungal inactivation, surface transformation, and etching is shown in Fig. 3e.

The increased water absorption and reduced microorganisms may enhance growth rate and germination percentage of rice seed. Therefore, we performed a germination test by placing approximately 100 treated seeds and 100 untreated seeds on moist seed germination paper to observe the effectiveness of corona plasma for seed sterilization and germination enhancement. The seedling quality and germination percentage were observed and calculated on day 14 . The results show that seedborne pathogens mostly appear and grow as fungi on the natural seeds (see Fig. 3b). In contrast, the treated seedlings showed a very clean surface and were healthy without observable fungi (see Fig. 3d). The repeated experiment showed similar results of considerable reduction or inactivation of pathogenic fungi.

The germination percentage of nontreated seed is $90 \%$ and $98 \%$ for treated seed (Fig. 4a), confirming that cold plasma can enhance seed germination, leading to higher quality and crop yield. Therefore, cold plasma offers the potential method for seedborne pathogenic fungi elimination for both before and after the harvesting process. However, how cold plasma influences seed storability becomes more interesting because the prolonged storage can significantly reduce seed viability and germination capacity. ${ }^{8}$ Many reports show that the accelerated aging (AA) process accurately predicts the field emergence under environmental stress conditions. ${ }^{28}$ Therefore, the AA process was performed to observe the potential use of the corona plasma for seed storage extension and quality retention. Seeds were exposed to typical accelerated aging temperatures

Volume 10, Issue 3, 2020 

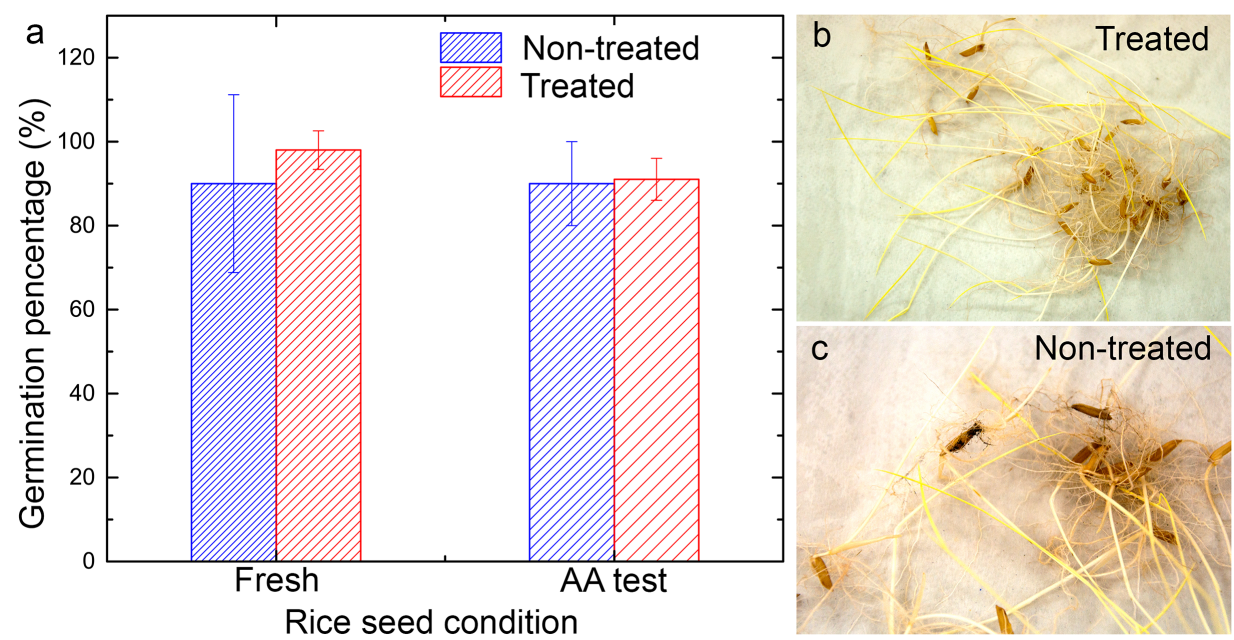

FIG. 4: Germination percentage and seedling quality before and after 60 days of storage. (a) Germination percentage of rice seedling at 14 days after set to germinate of untreated and treated seed at right after treatment, and (left) and after storing for 60 days (right). (b-c) Seedling quality of treated and untreated seeds on day 14 . The error bar denotes the confidence intervals; $n=4, P$ $<0.05$ (100 seeds per replicate).

$\left(45^{\circ} \mathrm{C}\right)$ and high relative humidity $(100 \% \mathrm{RH})$, leading to rapid seed deterioration. (see Materials and Methods). Figure $4 \mathrm{a}$ (right) shows that the germination test on non-treated seeds after AA is $90 \%$ (blue bar). The result suggests that, after prolonged storage, the germination of the plasma-treated seed is slightly reduced to $90 \%$ (see Fig. 4a, left red bar), similar to that of the original seed (untreated and no AA process). In contrast, germination of untreated seeds before and after the AA process is the same at $90 \%$ (see Fig. 4a, blue bar). Therefore, the standard germination and AA test results suggest that seed vigor is enhanced immediately after plasma treatment and slightly reduced after storage. The higher seed vigor is probably the result of the interaction between seeds and RONS that play an essential role in surface modification and decontamination. Although the AA occurs under moist conditions, unlike commercial seed storage under dry conditions, there is still much to learn about the economic and biological effects of corona plasma on rice seed storage. Thus, corona plasma is a promising method for large-scale seed storage applications.

\section{MATERIALS AND METHODS}

\section{A. Corona Plasma Configuration}

A high-voltage generator was connected to top metal tips. The electrode distance was 1 $\mathrm{cm}$. Ar gas was injected into atmospheric air microcorona discharge plasma at a rate of $\sim 2 \mathrm{~L} / \mathrm{min}$. 


\section{Wettability Measurement}

A well-controlled micropipette (LMP20 2-20 $\mu \mathrm{L}$ ) was used to apply $2 \mu \mathrm{L}$ on the rice seed surface for apparent contact angle (ACA), and water imbibition (WI) measurement. ACA and WI were measured under a digital optical microscope in conjunction with computer-aided measurement.

\section{B. Germination and Accelerated Aging Tests}

Germination testing of 100 treated and 100 untreated seeds were implemented following ISTA ${ }^{29}$ with four replicates of each. For the accelerated aging test, rice seeds were treated at $45^{\circ} \mathrm{C}$ and $100 \%$ relative humidity for 3 days to induce artificial aging. ${ }^{8}$

\section{Optical Emission Spectroscopy}

Optical emission spectroscopy (OES) was carried out using Thorlabs Compact Spectrometer (CCS200, Germany) to qualitatively analyze plasma components.

\section{Scanning Electron Microscopy}

Dry seeds with a moisture content of $5 \%$ to $8 \%$ were stubbed for SEM at $25 \pm 3^{\circ} \mathrm{C}$. Images were acquired with a Hitachi SU 1500 (Japan).

\section{E. Finite Element Method Simulation}

The electrostatic field distribution in the corona plasma configuration was simulated via COMSOL Multiphysics.

\section{CONCLUSIONS}

Corona plasma treatment has been demonstrated to be a promising method for decontaminating fungi associated with rice seeds while maintaining product quality and extending the shelf life. Germination enhancement via cold plasma is obtained by modifying the surface wettability without leaving any chemical residues. In contrast, using fungicide carries serious concerns about chemical residues in food products, which presents economic problems. Therefore, cold plasma pretreatment of seeds is a new approach to assist the germination and survival of very important food crops. The change in seed surface morphology is one critical factor for increased water permeability and is considered safe. However, the mechanisms underlying improved germination of seeds and the plasma interaction on seed surface are not yet fully understood. Before this technology can be scaled up for industrial applications, in-depth studies of interactions between plasma and the seed-surface must be conducted. 


\section{ACKNOWLEDGMENT}

This research was supported by the Program Management Unit for Human Resources \& Institutional Development, Research and Innovation; Office of National Higher Education Science Research and Innovation Policy Council, Thailand (Grant No. B05F630037).

\section{REFERENCES}

1. Selcuk M, Oksuz L, Basaran P. Decontamination of grains and legumes infected with Aspergillus spp. and Penicillum spp. by cold plasma treatment. Bioresour Technol. 2008;99(11):5104-9.

2. Rossman AY. The impact of invasive fungi on agricultural ecosystems in the United States. In: Langor D, Sweeney J, editors. Ecological impacts of non-native invertebrates and fungi on terrestrial ecosystems. Dordrecht: Springer Netherlands; 2009. p. 97-107.

3. Bradley CA. Effect of fungicide seed treatments on stand establishment, seedling disease, and yield of soybean in North Dakota. Plant Dis. 2008;92(1):120-5.

4. Misra NN, Yadav B, Roopesh MS, Jo C. Cold plasma for effective fungal and mycotoxin control in foods: Mechanisms, inactivation effects, and applications. Compr Rev Food Sci Food Saf. 2019;18(1):106-20.

5. Bhaskara Reddy MV, Arul J, Angers P, Couture L. Chitosan treatment of wheat seeds induces resistance to Fusarium graminearum and improves seed quality. J Agric Food Chem. 1999;47(3): 1208-16.

6. Panngom K, Lee SH, Park DH, Sim GB, Kim YH, Uhm HS, Park G, Choi EH. Non-thermal plasma treatment diminishes fungal viability and up-regulates resistance genes in a plant host. PLoS One. 2014;9(6):e99300.

7. Molina J, Sikora M, Garud N, Flowers JM, Rubinstein S, Reynolds A, Huang P, Jackson S, Schaal BA, Bustamante CD, Boyko AR, Purugganan MD. Molecular evidence for a single evolutionary origin of domesticated rice. Proc Natl Acad Sci U S A. 2011;108(20):8351-6.

8. Kapoor N, Arya A, Siddiqui MA, Kumar H, Amir A. Physiological and biochemical changes during seed deterioration in aged seeds of rice (Oryza sativa L.). Am J Plant Physiol. 2011;6(1):28-35.

9. Šerá B, Špatenka P, Šerý M, Vrchotová N, Hrušková I. Influence of plasma treatment on wheat and oat germination and early growth. IEEE Trans Plasma Sci. 2010;38(10 Pt 2):2963-8.

10. Srisonphan S, Ruangwong K, Thammaniphit C. Localized electric field enhanced streamer cold plasma interaction on biological curved surfaces and its shadow effect. Plasma Chem Plasma Process. 2020;40(5):1253-65.

11. Khamsen N, Onwimol D, Teerakawanich N, Dechanupaprittha S, Kanokbannakorn W, Hongesombut K, Srisonphan S. Rice (Oryza sativa L.) seed sterilization and germination enhancement via atmospheric hybrid nonthermal discharge plasma. ACS Appl Mater Interfaces. 2016;8(30):19268-75.

12. Heinlin J, Morfill G, Landthaler M, Stolz W, Isbary G, Zimmermann JL, Shimizu T, Karrer S. Plasma medicine: Possible applications in dermatology. J Dtsch Dermatol Ges. 2010;8(12):968-76.

13. Fridman G, Friedman G, Gutsol A, Shekhter AB, Vasilets VN, Fridman A. Applied plasma medicine. Plasma Process Polym. 2008;5(6):503-33.

14. Bogaerts A, Neyts E, Gijbels R, Van der Mullen J. Gas discharge plasmas and their applications. Spectrochim Acta B. 2002;57(4):609-58.

15. Teerakawanich N, Kasemsuwan V, Jitkajornwanich K, Kanokbannakorn W, Srisonphan S. Microcorona discharge-mediated nonthermal atmospheric plasma for seed surface modification. Plasma Chem Plasma Process. 2018;38(4):817-30.

16. Chang JS, Lawless PA, Yamamoto T. Corona discharge processes. IEEE Trans Plasma Sci. 1991;19(6):1152-66. 
17. Sang HN, Nelson SO. Dielectric properties of rice at frequencies from $50 \mathrm{HZ}$ to $12 \mathrm{GHZ}$. Trans ASAE. 1989;32(3):991-8.

18. Arora R, Mosch W. High voltage and electrical insulation engineering. In: High voltage and electrical insulation engineering. Hoboken, NJ: John Wiley and Sons; 2011.

19. Srisonphan $\mathrm{S}$. Tuning surface wettability through hot carrier initiated impact ionization in cold plasma. ACS Appl Mater Interfaces. 2018;10(13):11297-304.

20. Srisonphan S, Jitkajornwanich K. Nearly ballistic electron transport in an out-of-plane nanoscale defect-void channel. IEEE Trans Electron Devices. 2018;65(6):2601-6.

21. Srisonphan S, Hongesombut K. Tuning the ballistic electron transport of spatial graphene-metal sandwich electrode on a vacuum-silicon-based device. RSC Adv. 2015;5(3):2032-7.

22. Országh J, Danko M, Ribar A, Matejčík Š. Nitrogen second positive system studied by electron induced fluorescence. Nucl Instrum Methods Phys Res B. 2012;279:76-9.

23. Graves DB. The emerging role of reactive oxygen and nitrogen species in redox biology and some implications for plasma applications to medicine and biology. J Phys D: Appl Phys. 2012;45(26):263001.

24. Misra NN, Jo C. Applications of cold plasma technology for microbiological safety in meat industry. Trends Food Sci Technol. 2017;64:74-86.

25. Rifna EJ, Ratish Ramanan K, Mahendran R. Emerging technology applications for improving seed germination. Trends Food Sci Technol. 2019;86:95-108.

26. Chizoba Ekezie FG, Sun DW, Cheng JH. A review on recent advances in cold plasma technology for the food industry: Current applications and future trends. Trends Food Sci Technol. 2017;69:46-58.

27. Tawfick S, De Volder M, Copic D, Park SJ, Oliver CR, Polsen ES, Roberts MJ, Hart AJ. Engineering of micro- and nanostructured surfaces with anisotropic geometries and properties. Adv Mater. 2012;24(13):1628-74.

28. TeKrony DM. Accelerated aging test: Principles and procedures. Seed Technology. 2005;27(1):135-46.

29. Marcos-Filho J. Seed vigor testing: An overview of the past, present and future perspective. Sci Agr. 2015;72:363-74.

Volume 10, Issue 3, 2020 
